\title{
A COMPARATIVE KARYOTYPE STUDY IN SEVERAL SPECIES OF JAPANESE LOACHES (PISCES, COBITIDAE)
}

\author{
SHINYA HITOTSUMACHI, MOTOMICHI SASAKI* AND YOSHIO OJIMA
}

Biological Laboratory, Faculty of Science, Kwansei Gakuin University, Nishinomiya 662,
and *Zoological Institute, Hokkaido University, Sapporo 060

Received May 9, 1969

The loaches common in Japan, as fresh-water teleosts of the family Cobitidae, comprise nine species belonging to five genera. Chromosomal studies of several cobitiid species were made by Makino (1941), Kobayashi (1966) and Nogusa (1960) by means of the classical testissection methods, with the discussion on their karyological relationship. Class Pisces was a group of vertebrates in which chromosome studies have progressed comparatively less than in other groups. Current advances in squash techniques with the use of colchicine and hypotonic solution pretreatments allow more precise and reliable analysis of chromosomes than were possible with older sectioning and staining procedures. Classic concepts of the fish chromosomes have now been revised with new findings. Recently, a brief account of the chromosomes of Misgurnus anguillicaudatus, a member of the Cobitidae, was given by Hitotsumachi and Sasaki (1967) with the air-drying technique.

The present paper deals with the karyotype analyses of five species of the Cobitidae, with particular concern to cytotaxonomy in this group.

\section{MATERIALS AND METHODS}

The following species of the Cobitidae were subjected to the present chromosomal study: 1) Misgurnus anguillicaudatus, collected in Barato near Sapporo in April and May, 2) Barbatula toni, secured in Nopporo near Sapporo in June, 3) Lefua nikkonis, obtained in Nopporo in June, 4) Cobitis delicata, secured in Nakatsugawa, Gifu Prefecture, in July, and 5) Cobitis biwae, collected in Sanda, Hyogo Prefecture, in September.

For chromosome study, specimens were injected intraperitoneally with colchicine solution at the dosage of $1 \gamma$ per $1 \mathrm{~g}$ body weight $3-8$ hours before sampling. Testes, kidneys and gills, were freshly removed, minced with scissors, suspended in $0.075 \mathrm{M}$ $\mathrm{KCl}$ or $0.6 \%$ sodium citrate for 20 minutes at room temperature, and fixed with Carnoy's solution. Chromosome spreading was achieved through the routine air-drying method in combination with Giemsa staining.

\section{RESULTS}

Results of the present study with five species are presented in Table 1. Metaphase 
chromosomes from each animal were photographed and karyotyped. The chromosome numbers of four species except Cobitis biwae were established as 50 in $2 n$ in both spermatogonial and somatic metaphases. The primary spermatocytes showed 25 bivalents in each species (Fig. 1). The same number was again obtained in the secondary spermatocytes (Fig. 2). Karyotype analyses revealed, however, a characteristic chromosome morphology for each species.

Table 1. Chromosome numbers of five species of loaches studied.

\begin{tabular}{lccc}
\multicolumn{1}{c}{ Species } & $\begin{array}{c}\text { No. of } \\
\text { specimens }\end{array}$ & $\begin{array}{c}\text { Diploid } \\
\text { number }\end{array}$ & $\begin{array}{c}\text { Haploid } \\
\text { number }\end{array}$ \\
\hline Misgurnus anguillicaudatus & $5 \hat{\delta}, 2$ 우 & $50(155)$ & $25(4)$ \\
Barbatula toni & $3 \hat{\delta}, 2$ 우 & $50(126)$ & $25(4)$ \\
Lefua nikkonis & $3 \hat{\delta}, 4$ 우 & $50(71)$ & $25(104)$ \\
Cobitis delicata & $4 \hat{\delta}, 3 ?$ & $50(54)$ & $25(12)$ \\
Cobitis biwae & 1 ? 1 우 & $96(22)$ & \\
\hline
\end{tabular}

( ): total no. of cells observed.

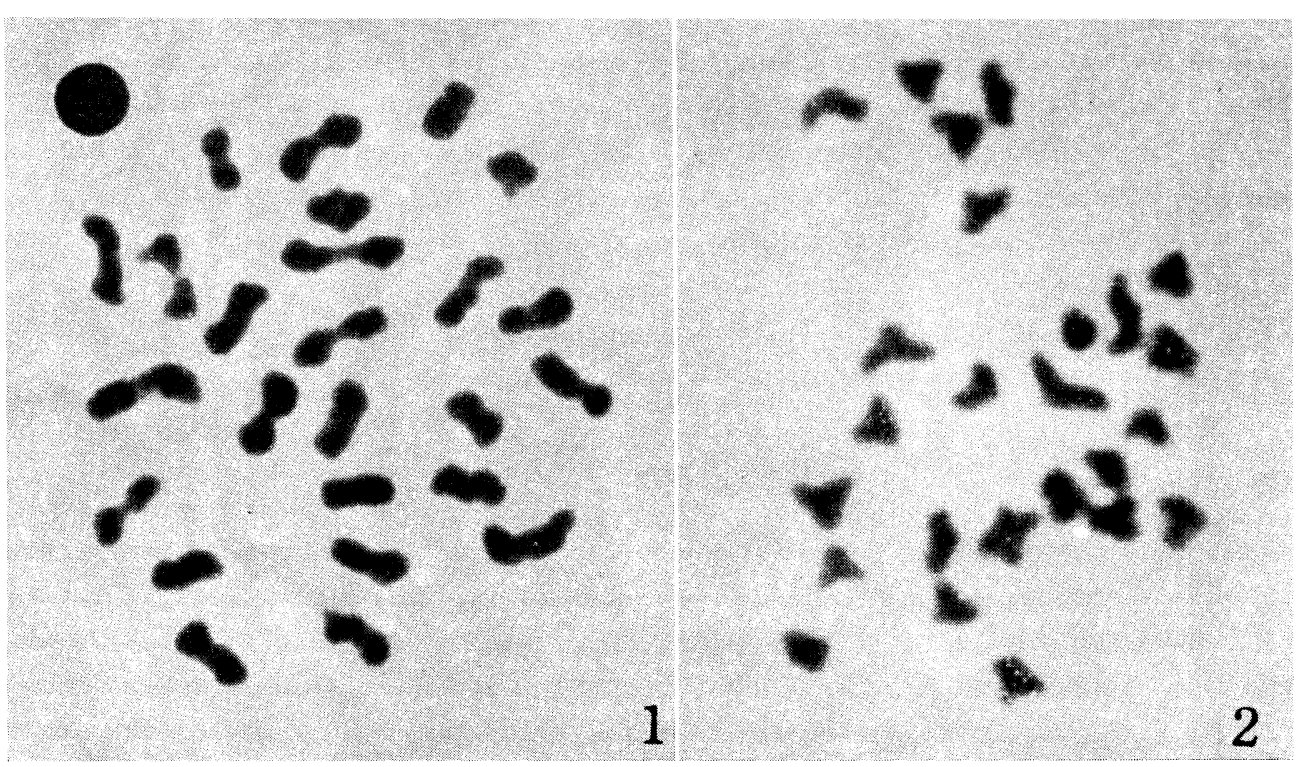

Fig. 1. Primary spermatocyte of Cobitis delicata, showing 25 bivalents. $\times 3000$.

Fig. 2. Secondary spermatocyte of Barbatula toni, showing 25 chromosomes. $\times 4600$.

The diploid complex of Misgurnus anguillicaudatus consisted of 7 pairs of meta- to submetacentric and 18 pairs of telocentric elements (Fig. 3).

The diploid complement of Barbatula toni comprised 8 pairs of meta- to submetacentrics and 17 pairs of telo- to subtelocentrics (Fig. 4).

The 50 chromosomes of Lefua nikkonis were made up of 6 pairs of meta- to submetacentrics and 19 pairs of telo- to subtelocentric chromosomes (Fig. 5).

The diploid complement of Cobitis delicata consisted of 9 pairs of meta- to submetacentric and 16 pairs of telo- to subtelocentric elements (Fig. 6). 
16 $868 \pi \times \times \times 8 \times 8 \times x$

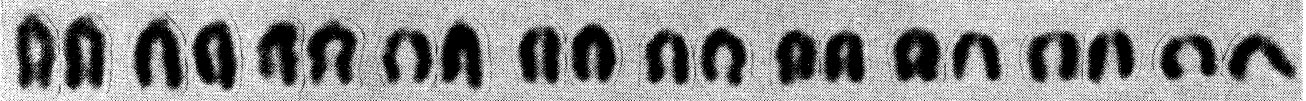
A1) ลa no na va na con an 3

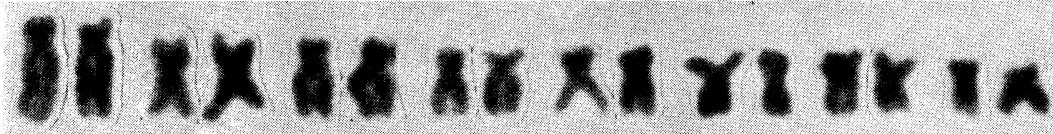

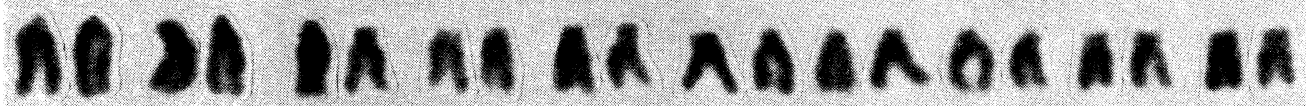

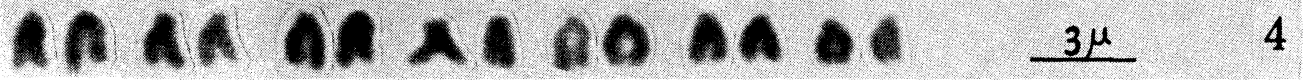

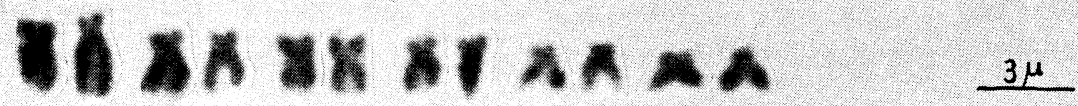

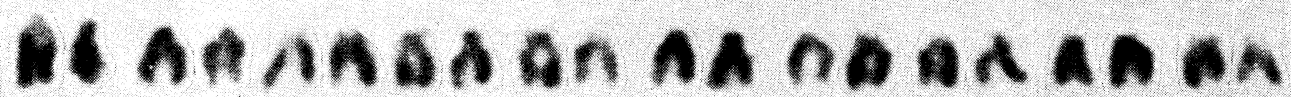

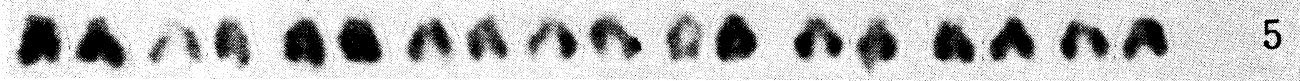

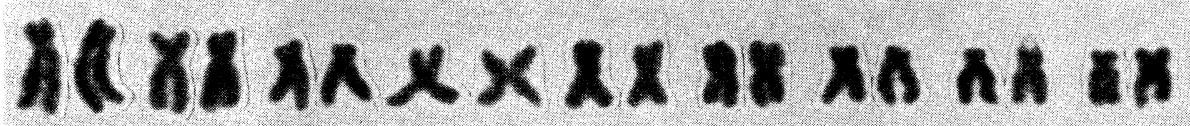
UR MQ Aa an da on nannat as DO nอ ลด อO คA อก $3 \mu \quad 6$

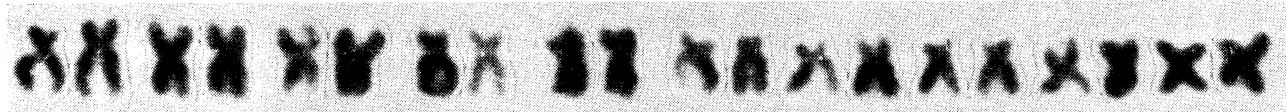

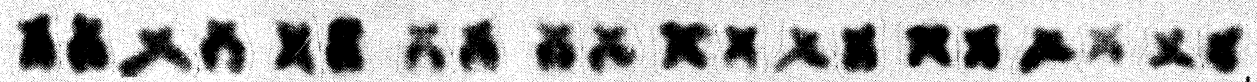

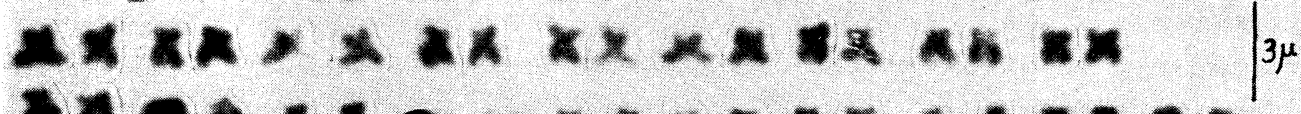

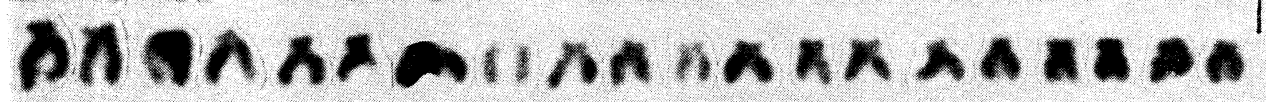

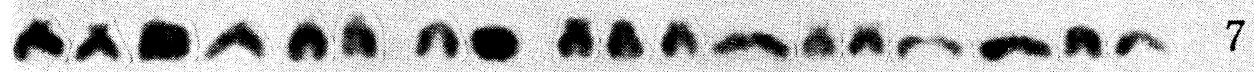

Figs. 3-7. Karyotype analyses in five species of Cobitidae.

3, Misgurnus anguillicaudatus, 50 chromosomes. 4, Barbatula toni, 50 chromosomes. 5, Lefua nikkonis, 50 chromosomes. 6, Cobitis delicata, 50 chromosomes. 7, Cobitis biwae, 96 chromosomes. 
The first pair of meta- to submetacentric group was easily identified in each species on account of their remarkable large size. Other elements showed, however, a gradual seriation in size and shape.

In striking contrast to the above species, Cobitis biwae was characterized by 96 chromosomes in $2 n$. They consisted of 29 pairs of meta- to submetacentrics and 19 pairs of telo- to subtelocentrics with a gradual reduction in length (Fig. 7).

Comparison of the chromosomes of the above species between the two sexes, except Cobitis delicata in which male and sexually undetermined specimens were studied, has failed to demonstrate morphological difference among individual chromosomes.

\section{DISCUSSION}

The diploid number of Misgurnus anguillicaudatus was revised as 50 by Hitotsumachi and Sasaki (1967). The present findings also showed the diploid number of 50 for Barbatula toni and 96 for Cobitis biwae. Modern technical methods have thus revised the chromosome numbers of the above species, so far as the present materials are concerned.

It was shown that the following four species, Misgurnus anguillicaudatus, Barbatula toni, Lefua nikkonis and Cobitis delicata, were characterized by specific karyotypes distinguishable from one another, though they had the same number of 50 . The 50 chromosomes were reported in Lefua echigonia, one of Japanese loaches by Nogusa (1960), and in the khulli loach of Southeast Asia, Acanthophthalmus khulli, by Muramoto et al. (1968). On the above basis, it appears that the basic diploid number of the family Cobitidae is 50 and, that some structural rearrangements produce the chromosome complement characteristic of each species.

Ohno and Atkin $(1966,1967)$ proposed polyploidization of the original vertebrate genome as a facter of vertebrate evolution; they found a diploid-tetraploid relationship in the family Cyprinidae on the basis of both the chromosome complement and DNAcontents. It seems that Cobitis biwae here studied may be a tetraploid species in the family Cobitidae because of its high chromosome number. Muramoto et al. (1968) noted that the chromosome number of the clown loach, Botia macracantha, was 98 , but its DNA-value was similar to that of the khulli loach whose diploid number was 50 . Thus, the photometrical study of DNA in Cobitis biwae and other members of this group is of special interest in future in order to learn the correlation between the chromosome number and DNA-amounts.

\section{SUMMARY}

The chromosomes were studied in five species of cobitiid loaches with the application of current air-drying techniques. It was found that Misgurnus anguillicaudatus, Barbatula toni, Lefua nikkonis and Cobitis delicata had the same diploid number of 50 . Comparison of karyotypes revealed the chromosome morphology characteristic of each species. In contrast, Cobitis biwae was remarkable by having 96 chromosomes. No 
evidence for sexual difference of chromosomes was obtained in the species studied here.

\section{ACKNOWLEDGMENTS}

The authors wish to express their gratitude to Professor Sajiro Makino for his valuable suggestion and going through the manuscript. Appreciation is also expressed to Dr. Hisashi Niwa for his kind aid in collecting Cobitis delicata.

\section{REFERENCES}

Hitotsumachi, S. and M. Sasaki, 1967 A note on the chromosomes of the loach (Misgurnus anguillicaudatus). Chromosome Information Service 8: 19-20.

Kobayasi, H., 1965 A chromosome study in inter-family hybrids between the funa and the loach. The Nucleus 8: 1-6.

Makino, S., 1941 The chromosomal relation between the two allied species of the loach (Cobitidae, Pisces). Cytologia 12: 79-82.

Muramoto, J., S. Ohno and N. B. Atkin, 1968 On the diploid state of the fish order Ostariophysi. Chromosoma 24: 59-66.

Nogusa, S., 1960 A comparative study of the chromosomes in fishes with paticular considerations on taxonomy and evolution. Mem. Hyogo Univ. Agric. 3: 1-62.

Ohno, S. and N. B. Atkin, 1966 Comparative DNA values and chromosome complements of eight species of fishes. Chromosoma 18: 455-466. -, J. Muramoto, L. Christian and N. B. Atkin, 1967 Diploid-tetraploid relationship among old-world members of the fish family Cyprinidae. Chromosoma 23: 1-9. 